\title{
Heat Dissipation Characteristics of a FSAE Racecar Radiator
}

\author{
Shreyas Padmaraman*, Nagarathnam Rajesh Mathivanan, Babu Rao Ponangi \\ Department of Mechanical Engineering, PES University, Bangalore 560085, India
}

Corresponding Author Email: 3459shreyas@gmail.com

https://doi.org/10.18280/ijht.390531

Received: 10 March 2020

Accepted: 18 August 2021

\section{Keywords:}

heat exchanger, FSAE race car, numerical modelling, radiator, Ricardo wave

\begin{abstract}
In recent times, the rise in performance and power of internal combustion engines has resulted in an increased demand for more efficient cooling systems. Customized engineered coolants, additives, radiator materials, redesigned coolant pumps and radiators help to meet these increased demands. In case of FSAE racecar, designing a radiator is an important part for controlling the engine operating temperature and increasing the effectiveness of the cooling system. In this work, an attempt is made to develop a simple yet reasonably accurate analytical model to calculate the effectiveness of a radiator. The model is then applied to predict the operating temperature of the engine at varying load conditions. Experimental investigations were performed using a customized radiator test rig to replicate the field test conditions. The rate of heat dissipation through the radiator with respect to the inlet temperature is analyzed by changing the surface area of the radiator. The developed model is able to predict the engine operating temperature in close agreement with the experimentation conducted. A marginal increase in surface area of the radiator resulted in significant drop in engine operating temperature. Thereby reduction in engine operating temperature will boost the performance of FSAE race car.
\end{abstract}

\section{INTRODUCTION}

The control of the operating temperature of an engine is crucial to its performance, emission generation, life span and durability of its components [1, 2]. An automobile heat exchanger (radiator) is responsible for maintaining the operating temperature within the desired range.

Sandeep and Deshmukh [3] indicate that in an internal combustion engine, a fraction of the input energy supplied by the fuel is converted to useful work. Typically, around $26 \%$ of the input energy is converted to useful mechanical work and is harnessed at the crankshaft of the engine. The remaining quantum of energy is converted to heat energy, which is dissipated in different manners. Roughly $44 \%$ of the total energy is lost through exhaust gases, $29 \%$ is dissipated through the cooling system and a small fraction is lost via convection and conduction through various engine components and lubricants.

Commercial automobiles are not keen on to deliver maximum performance at all times. As a result of this, most commercial radiators are designed to prevent the engine from overheating, without much emphasis on maintaining the engine temperature within a narrow operating range. On the other hand, a well-designed racecar cooling system is intended to maintain the engine within a small range of operating temperatures as well as to prevent the engine from overheating. The fluctuations in the operating temperature of an engine will be reduced, if the difference between the heat dissipated by the radiator and the heat supplied by the engine to the coolant is maintained minimal.

A schematic representation of the cooling system as seen on most FSAE racecars is shown in Figure 1, wherein thick lines represent flow of water, and the thin line represents the flow of air. The blue and red lines indicate low and high temperatures, respectively. As is shown, the primary link between the heat circuit, containing the heat source, and sink is the radiator.

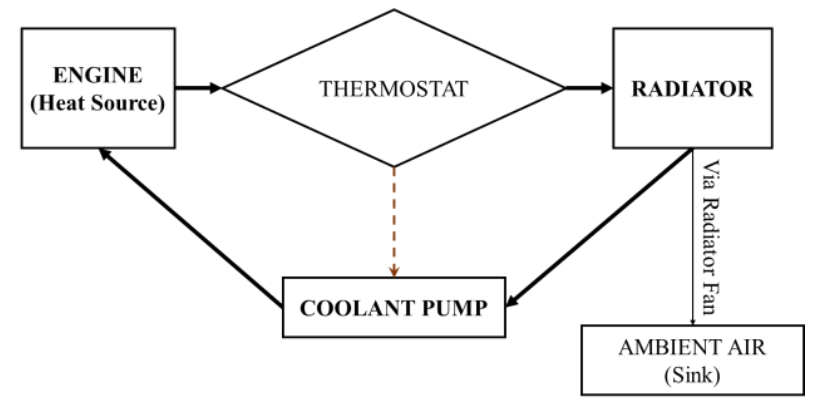

Figure 1. Racecar cooling system schematic diagram

The aluminum core of an automobile radiator consists of a series of ducts, which carry hot coolant, and fins to increase the overall effective area of heat transfer. Usually radiators are designed to operate as cross flow heat exchangers. The flow of cool air and hot coolant is mutually perpendicular to one another unlike in the case of parallel or counter flow heat exchangers. In the case of radiators for heavy motor vehicles, the hot coolant may pass through the core of the radiator more than once in order to increase the effectiveness of heat transfer of the radiator (multi pass heat exchangers).

In a bid to reduce the overall size and weight of cooling systems and radiators, it is beneficial to use water or oil-based coolants with a host of additives instead of distilled water as a coolant. As a result of this, there has been substantial research in the recent past [4-7] that has gone into synthesizing and 
evaluating newer additives. Advanced coolant additives provide greater control over the rate of heat absorption and rejection, control over corrosion, fouling, scaling as well as other physical properties. With recent research focusing on the addition of thermal nanoparticles to the coolant mixtures [5], radiators will only become more effective without significant increase in size and weight. Whereas, with regard to FSAE and Formula Student [8] competitions, it is mandate to use only distilled water as coolant. Hence design and optimization tasks pertaining to the application of any coolant additives cannot be carried out. Furthermore, the use of OEM radiators for cooling of their respective engines can prove to be inadequate due to its reduction in size. As a result, the design and development of cooling systems for FSAE racecars is restricted to the radiator fan [9], fan duct, coolant pump, radiator material and size.

The nature of air flow through a radiator core has a significant impact on radiator performance as investigated by Chunhui et al. [10]. In addition to simulating air flow through the radiator, Rishabh et al. [2] analysed the effect on heat transfer using CFD tools such as Siemens' Star CCM+ and predicted the temperature gradient and overall rate of heat transfer across the radiator.

Radiators are usually manufactured from aluminum even though materials such as, copper and brass offer lesser resistance to heat transfer. Conversely, copper-brass radiators are considerably heavier and more expensive when compared to aluminum radiators [9].

It is often tedious to alter the characteristics of the coolant pump that is integrated into the engine of most FSAE racecars as it would mean altering the gear ratios connecting the pump to the crankshaft. Hence, the common practice is to incorporate an external electric pump into the cooling system [11] based on design requirements and is advantageous even when the engine is turned off. Whereas when the pump is integrated to the engine, coolant will no longer be circulated through the system causing the engine temperature to surge past the operating range before cooling down. However, the downside is that such pumps add weight to the racecar which is not justified for the marginal gains it offers. Hence, it is of greater importance to design and optimize the size of a radiator core as it proves to be a more suitable alternative considering cost effectiveness, weight, feasibility and reliability.

When designing a cooling system, there are two critical operating conditions for the radiator which are influenced by engine rpm, vehicle speed and throttle position.

The first critical condition is when the engine is idling and the car is at a standstill. The second is when the engine is running under maximum load at a low vehicle speed [12]. When the car is at a standstill, the only source of airflow through the radiator, for cooling purposes, is the spinning radiator fan. Correspondingly, if the heat generated by the engine per unit flow rate of air through the radiator is calculated, it would be greatest for both the above cases in comparison to other rpm-speed-load conditions. However, for an FSAE racecar, the former scenario of the vehicle at a standstill is considered for design purposes as the engine is not continuously put through its paces and does not frequently reach peak load conditions [1].

Complex CFD models are currently being used to determine the operating temperature of the engines. These require considerable computational power, time and individual effort to achieve usable results. For instance, it takes upwards of nearly 50 working hours to develop a working knowledge of
ANSYS ${ }^{\circledR}$ Fluent in order to predict the temperature drop across a radiator for a specified air and coolant flow. Conversely, there are few analytical or numerical models that do not require the knowledge of any specific software, yet still deliver representative results. Therefore, it is imperative to characterize and predict the performance of a radiator using simpler yet accurate numerical models based on standard heat transfer relations, which do not require prohibitive computational power or resources.

An attempt is made in this paper to experimentally validate the results of a numerical model for a FSAE racecar radiator setup, and hence predict the operating temperature of the engine for different working conditions based on the effectiveness of the radiator as calculated using the numerical model.

\section{EXPERIMENTAL SET-UP}

Typically, FSAE teams conduct radiator experiments and tests on their racecars at specific race tracks to evaluate or validate the performance of the radiator. However, the dilemma present when working with dynamic engine load conditions, varying temperatures and air velocities is that there are many unaccounted variables and parameters whose effects cannot be studied, closely monitored or controlled. The ability to create a steady state condition for a system thus becomes advantageous when validating or experimenting with a radiator for these reasons and can be achieved on a test rig. Nevertheless, it is important to compare these testing results with controlled experimental and numerical results to understand the limitations and loses within the system.

The test rig was used to investigate the heat dissipation capability of an automobile heat exchanger. The test rig, shown in Figure 2, consists of an electric water pump, radiator, cooling fan, fan duct and electric heater. A rotameter, anemometer, and four thermometers were used to measure inlet and outlet temperatures of the radiator, air temperature after flowing through the core of the radiator and ambient air temperature respectively.

The advantage of this specific rig is that crucial variables such as inlet temperature, volume flow rates of air and water can be individually controlled. The outlet of the radiator was connected via hose pipes to a reservoir tank through which the water was heated using the electric heating element to the desired temperature. Since the selected hose pipes were considered to be good insulators and were relatively short in length, temperature drop across the hoses was assumed to be negligible. Heated coolant (water) was circulated through the system using the external electric pump at a volume flow rate of 9lpm which was controlled by a rotameter connected to the outlet of the pump. All four thermometers were connected to digital readouts that displayed the local, real-time temperature of their respective positions. All experiments were carried out at an ambient air temperature of $35^{\circ} \mathrm{C}$, which is the same as the on-track conditions encountered during testing.

The integrated coolant pump on the racecar is driven by a series of gears connecting it to the engine's crankshaft. There is hence a direct relation between the flow rate of coolant and the engine speed. The volume flow rate of coolant was measured across the range of engine speeds which will be encountered.

The coolant inlet temperature was varied from $70^{\circ} \mathrm{C}$ to $100^{\circ} \mathrm{C}$. The upper limit for this temperature range was 
constrained by the heating capability of the electric heater and the lower limit was decided based on the temperature at which the thermostat valve of the racecar's cooling system is designed to open.

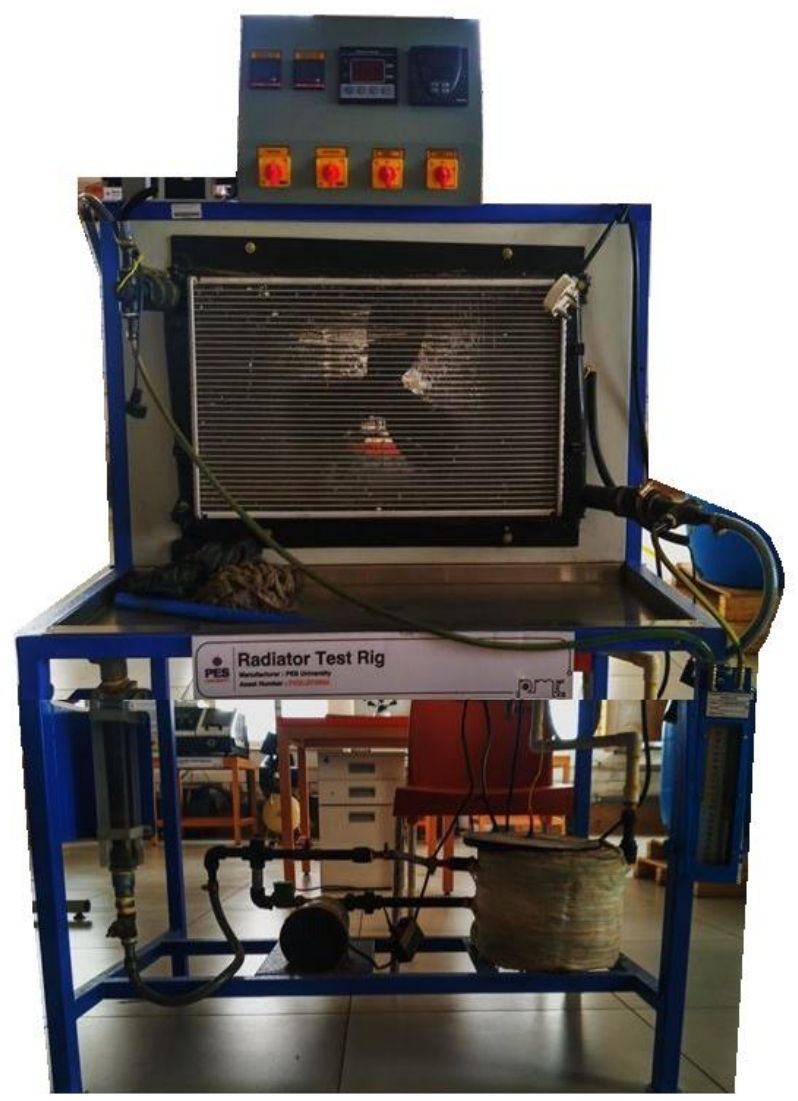

Figure 2. Radiator test-rig

The fan positioned behind the radiator on the test rig was controlled by a regulator in order to replicate the suction effect generated by the radiator fan used on the racecar. The average velocity of air downstream of the radiator was used an indication of the suction effect, and was found to be $1.2 \mathrm{~m} / \mathrm{s}$ on the racecar as measured using an anemometer. This air velocity due to the radiator fan, corresponds to the car is in standstill and idling position.

Having set the input conditions, the pump was switched on and the rotameter and cooling fan were adjusted to set the volume flow rate of water and the air velocity through the radiator core to their desired values. The heater was then switched on to raise the inlet temperature of water in steps across the desired range. Once steady state conditions were achieved for each step-in inlet temperature, measurements of the temperature of water at the radiator outlet and the temperature of air after passing through the radiator were recorded. Based on the temperature drop of water across the radiator, the heat dissipated by the radiator can be calculated using Eq. (1):

$$
\dot{Q}_{r}=\dot{\mathrm{m}}_{\mathrm{w}} c_{p}\left(T_{h, \text { in }}-T_{h, \text { out }}\right)
$$

On plotting the rate of heat rejected by the radiator and the rate of heat generated by the engine across a range of inlet temperatures, the operating temperature of the engine in terms of coolant temperature at the engine outlet can be deduced.

The radiator inlet temperature at which the rate of heat dissipated by the radiator is equal to the rate of heat generated by the engine is considered as the stable operating temperature of the engine, for the given steady state conditions.

\section{NUMERICAL MODELLING}

The performance of a radiator is characterized usually by either of two methods, $\varepsilon$-NTU relations and logarithmic mean temperature difference (LMTD). The $\varepsilon$-NTU method can be used to calculate radiator effectiveness based on its geometry, overall heat transfer coefficient and flow rate of the hot and cold fluid. The LMTD method can be used when the inlet and outlet temperatures of both fluids are known, without which the effectiveness of the radiator cannot be calculated. In this work, efforts are made to predict the inlet temperature of the radiator from its effectiveness; hence the LMTD method of evaluation cannot be adopted and therefore, the $\varepsilon$-NTU relations are used.

Measurements of the radiator were used to create a 3D CAD model (Figure 3) from which the surface area of the radiator core, across which heat transfer occurs, was calculated.

Considering that the radiator fins are short in length and have both ends at nearly the same temperature, they were classified as "short fins with insulated ends" for which the efficiency of the fins was calculated using Eq. (2) and Eq. (3) and its effective area of heat transfer $\left(A_{\text {fin-effective }}\right)$ using Eq. (4).

$$
\begin{array}{r}
m=\sqrt{\frac{h P}{k A}} \\
\eta_{f i n}=\frac{\tan (m L)}{m L}
\end{array}
$$

$$
A_{\text {fin-effective }}=A_{\text {fin }} \eta_{\text {fin }}
$$

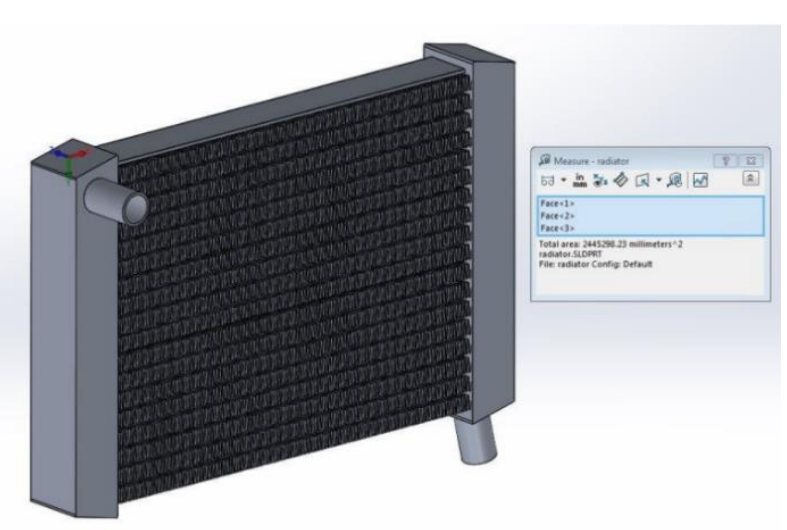

Figure 3. CAD model of the radiator

Since thin-walled aluminum ducts of the radiator core can be considered to have negligible thermal resistance, the total effective area of heat transfer $\left(\mathrm{A}_{\text {effective }}\right)$ was calculated using Eq. (6). The effectiveness of a radiator is defined as the ratio of the actual rate of heat rejection to the maximum possible rate of heat rejection (Eq. (5)).

$$
\varepsilon=\frac{\dot{Q}_{r}}{\dot{Q}_{r, \max }}=\frac{C_{h}\left(T_{h, \text { in }}-T_{h, \text { out }}\right)}{C_{\min }\left(T_{h, \text { in }}-T_{c, \text { in }}\right)}=\frac{C_{c}\left(T_{c, \text { out }}-T_{c, \text { in }}\right)}{C_{\min }\left(T_{h, \text { in }}-T_{c, \text { in }}\right)}
$$

The theoretical effectiveness of the radiator was calculated using the following set of standard relations [13]: 


$$
\begin{gathered}
A_{\text {effective }}=A_{\text {ducts }}+A_{\text {fin-effective }} \\
N T U=\frac{U A_{\text {effective }}}{C_{\min }} \\
\varepsilon=1-e^{\left\{\left(\frac{C_{\min }}{C_{\max }}\right)^{-1}(N T U)^{0.22}\left[e^{\left[-\frac{C_{\min }}{C_{\max }}(N T U)^{0.78}\right]}-1\right]\right\}}
\end{gathered}
$$

Since the engine operating temperature is indicated by the radiator inlet temperature, the terms from Eq. (5) can be rearranged to calculate the radiator inlet temperature (Eq. (9))

$$
T_{\text {engine }}=T_{h, \text { in }}=\frac{\dot{Q}_{r}}{\varepsilon C_{\min }}+T_{c, \text { in }}
$$

Ricardo WAVE is a 1-D gas dynamics simulation tool, which solves Navier-Stokes equations (Conservation of mass, momentum and energy for compressible gas flows). Using this 1-D engine simulation tool, the actual rate of heat rejected to the cooling system and engine components by the combustion process $\left(\dot{Q}_{r}\right)$ was obtained (Figure 4 ) for various rpm-throttle conditions. Using this array of values, the operating temperature of the engine was predicted for each rpm-throttle combination using Eq. (9).

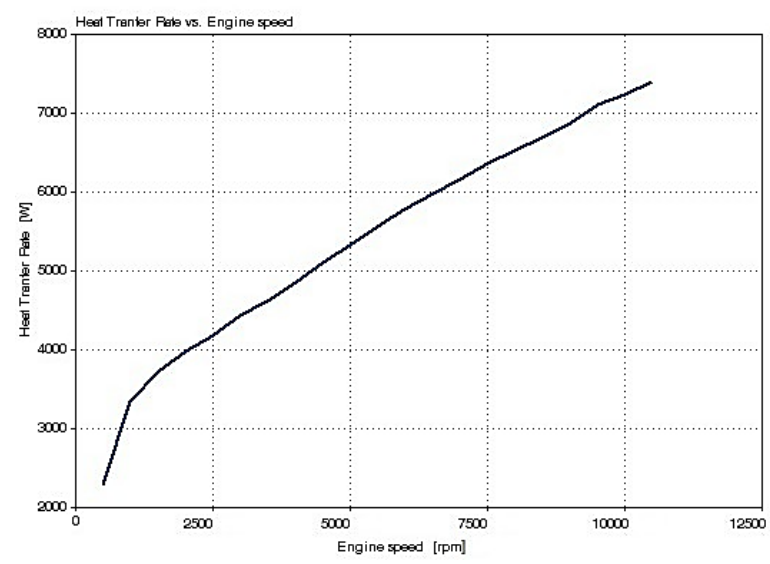

Figure 4. Heat rejected by the engine for a range of engine speeds at $0 \%$ throttle input (idling)

\section{RESULTS AND DISCUSSION}

The desired operating temperature of the engine on a KTM Duke 390 , which is the engine being used on our formula student racecar, is between $95^{\circ} \mathrm{C}$ and $102^{\circ} \mathrm{C}$. This range of operating temperatures was chosen based on parameters and data from the engine manufacturer.

\subsection{Accuracy of the model at design conditions}

The rate of heat dissipation through the radiator was calculated from the experimental data as well as the $\varepsilon$-NTU method across different radiator inlet temperatures for an engine speed of $3000 \mathrm{rpm}$ and plotted against inlet/engine temperature as shown in Figure 5. The engine operating temperature was deduced by the intersection of the radiator heat dissipation curves $\left(\dot{Q}_{r}\right)$ with the engine heat generation curve $\left(\dot{Q}_{e}\right)$ and was calculated to be $105.27^{\circ} \mathrm{C}$ from experimental data and $101.91^{\circ} \mathrm{C}$ from $\varepsilon-\mathrm{NTU}$ method.

From Figure 5, it is seen that there is a maximum deviation of $8.2 \%$ and root mean square error of $4.5 \%$ between experimental and analytical heat transfer rate.

During field testing of the car on the racetrack, the stable operating temperature of the engine as indicated by the system's inbuilt temperature sensors was recorded to be $107^{\circ} \mathrm{C}$ at an engine idling speed of 3000rpm. The deviation of the analytical results from the test results can be explained by the effect of a few unaccounted variables as well as assumptions made in order to simplify the model for the desired operating conditions.

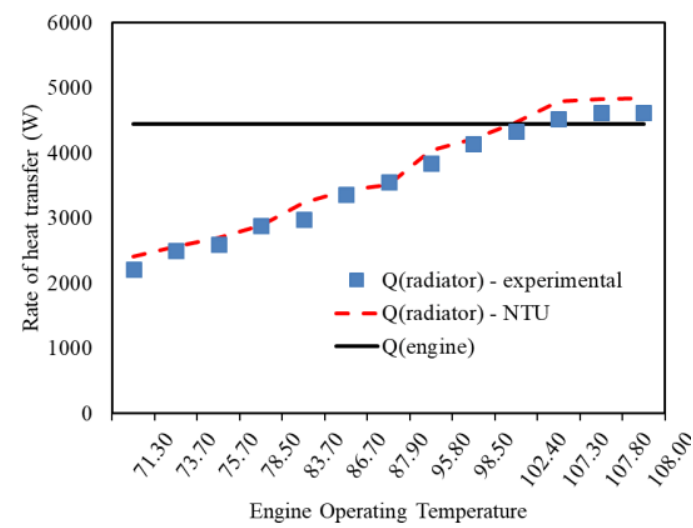

Figure 5. Radiator heat rejection curves of the OEM radiator for different inlet temperatures

Firstly, in FSAE racecars, convection across the surface of the engine and other heated powertrain elements such as the exhaust also contribute to the cooling of the engine as they are not covered by body panels and are exposed to the ambient air. However, due to the engine's irregular surface geometry, it is hard to accurately estimate the extent of convective cooling using standard heat transfer relations. At a standstill, the heat loss due to free convection is known to be negligible; however, when the vehicle is in motion, the cooling due to forced convection begins to have a considerable impact on the cooling of the engine.

Secondly, in order to easily estimate the mass flow rate of air through the radiator, the effect of the wake and turbulence caused by components upstream of the radiator on the racecar were neglected. It was calculated based on the average measured discharge coefficient of the radiator core and the free stream velocity of air. The discharge coefficient of the radiator core was found to be 0.75 across a wide range of free stream air velocities under laboratory test conditions. This finding is applicable for low vehicle speeds as are commonly encountered in FSAE competitions.

Figure 6 shows the car used in the study highlighting the KTM engine used and the display where the coolant temperature is indicated on the top right corner. The data from the OEM temperature sensor, integrated into the engine block, was fed to the racecar's ECU and then displayed temperature in ${ }^{\circ} \mathrm{C}$ on the cockpit digital LCD display. The black arrow indicates the position of the temperature sensor on the engine block; the red arrow indicated the direction of flow of hot coolant and the blue arrow indicates the direction of flow of cool coolant.

A common source of losses in cooling effectiveness which is often difficult to account for is due to the induction of air bubbles in the cooling system. Improper bleeding technique and leakages in the coolant lines results in the formation of such air bubbles. Air having a low specific heat capacity, 
makes it a good insulator thereby reducing the heat absorption and dissipation capability of the radiator, and hence its effectiveness.

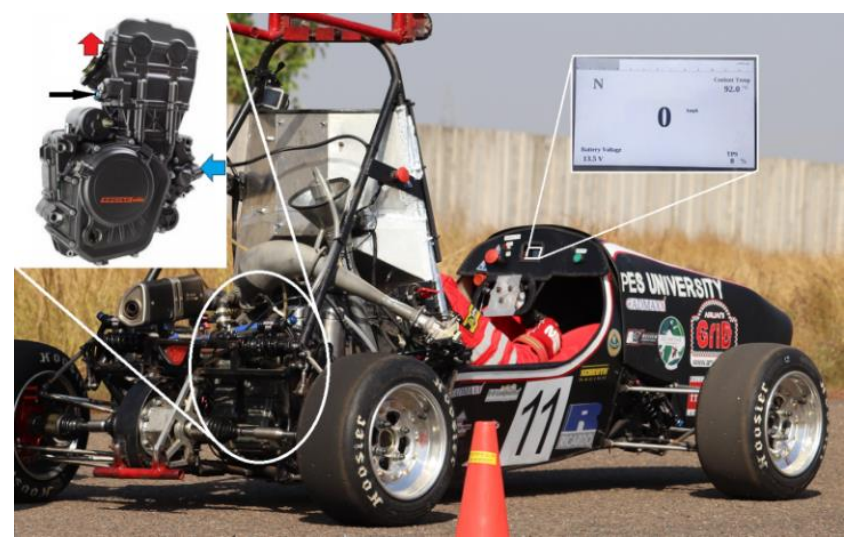

Figure 6. Formula student race car used in the present study

For the engine speed of 3000rpm considering the racecar to be at a standstill, the radiator effectiveness calculated using experimental data was found to be 0.81 at the predicted engine operating temperature. This is within $10 \%$ of the effectiveness calculated using the $\varepsilon$-NTU method which was found to be 0.85 . However, it was observed that the OEM radiator provided insufficient cooling for the engine under the rules and regulations of formula student competitions, which only permit the use of pure distilled water as coolant. Hence, a custom radiator was designed and manufactured using the numerical model explained in section 3 , by predicting the operating temperature of the engine for various engine speeds and throttle positions. Table 1 shows the difference in key dimensions between the custom and OEM radiators.

Figure 7 shows the predicted temperature profile when the racecar is driven in first gear across different engine speeds for various throttle positions when cooled by the OEM radiator.

Racecars in FSAE competitions run at vehicle speeds between $20 \mathrm{kmph}$ to $70 \mathrm{kmph}$ and operate predominantly at engine speeds ranging from 5000-9000rpm. As explained previously in section 1 , there are two possible critical conditions for any cooling system of which an FSAE racecar's corresponds to the condition of the engine idling when the racecar is at a standstill. With the radiator designed for the critical condition, and the operating conditions frequently lying in the low rpm-load conditions, the assumptions stated to simplify the model are effective. The analytical model can hence be considered reasonably accurate within these operating conditions and can be used for predictive purposes.

Figure 8 shows the predicted temperature distribution for the custom radiator which has been manufactured and tested for the current generation of our racecar. The new radiator has a larger core area and larger volume which corresponded to better cooling across engine speeds and load conditions, as observed from track testing.

Table 1. Dimensions of radiators used

\begin{tabular}{|c|c|c|}
\cline { 2 - 3 } \multicolumn{1}{c|}{} & $\begin{array}{c}\text { OEM } \\
\text { Radiator }\end{array}$ & $\begin{array}{c}\text { Custom } \\
\text { Radiator }\end{array}$ \\
\hline Width (mm) & 291 & 220 \\
\hline Height $(\mathrm{mm})$ & 192 & 380 \\
\hline Depth $(\mathrm{mm})$ & 38 & 38 \\
\hline $\begin{array}{c}\text { External Surface Area } \\
\left(\mathrm{mm}^{2}\right)\end{array}$ & 2789273.37 & 3068558.85 \\
\hline
\end{tabular}

The numerical model predicted that the custom radiator would maintain the engine temperature at $87.43^{\circ} \mathrm{C}$ for an idle speed of $3000 \mathrm{rpm}$ which is within $5 \%$ of the actual engine operating temperature of $92^{\circ} \mathrm{C}$, as observed from field tests.

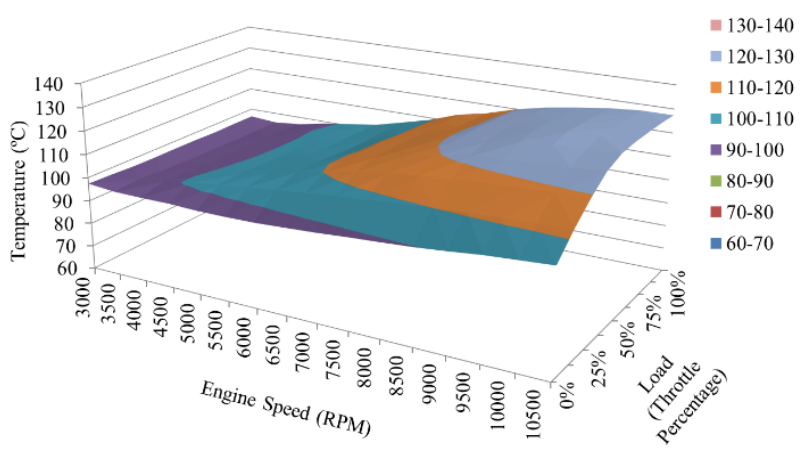

Figure 7. Variation of engine temperature with engine speed and throttle percentage for the OEM radiator

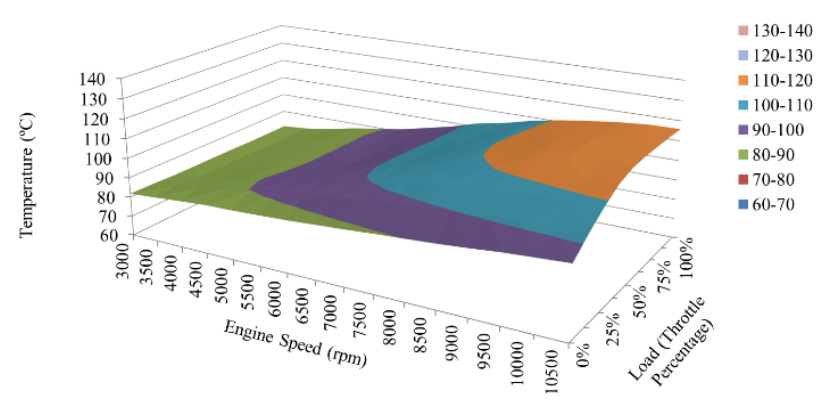

Figure 8. Variation of engine temperature with engine speed and throttle percentage for a custom radiator

\subsection{Accuracy of the model at extreme operating conditions}

Although a drastic rise in operating temperature of the engine in the region of high engine speed and high load conditions is observed (Figure 7,8), these conditions are often evaded as a result of the track layout commonly encountered at FSAE competitions. As it can be observed in the contour plots, the coolant inlet temperature is predicted to exceed $110^{\circ} \mathrm{C}$, at high engine speeds and high throttle positions. At these elevated temperatures, past the boiling point of water at $1.4 \mathrm{bar}$, it is complicated to model the heat exchanger using the $\varepsilon$-NTU method as a fraction of the coolant is in the vapor state and remaining in liquid state (two-phase flows). The physical properties such as heat capacity and mass flow are problematic to estimate for such a system.

The deviations at higher engine speeds and load conditions can be explained by the following, in addition to the effect of the assumptions described previously.

Difference between the true air-fuel ratio of the engine and the 1D engine model can result in different values of heat generation of the order of hundred watts, as the true air-fuel ratio is affected by the life of the engine, local temperatures within the cylinder, health of the spark plug and other parameters which are difficult to model. The heat lost due to convection through the engine oil and conduction through engine parts in the 1D engine model are accurate but not exact as the software limits the input of the geometry of engine parts and properties of engine fluids. It is important to realize these limitations without which the results can be misinterpreted. 


\section{CONCLUSIONS}

The validation of the radiator numerical model was successfully conducted using a custom-built radiator test rig and field-testing results. In predicting the engine operating temperature for a specified engine speed has led to the following conclusions:

- The effectiveness of the radiator was numerically calculated to be 0.85 and had a deviation of less than $10 \%$ when compared to the experimental results, with the engine idling at a speed of 3000rpm and the vehicle at a standstill.

- The operating temperature of the engine using the custom radiator was successfully predicted to be $87.43^{\circ} \mathrm{C}$ at an engine idling speed of 3000rpm and had a deviation of less than $5 \%$ when compared to the field testing results.

- An increase in the area of the radiator core by $10 \%$ from the stock radiator will result in an average of $10.8 \%$ (maximum $15^{\circ} \mathrm{C}$ ) reduction in the operating temperature of the engine.

From these results, it is concluded that the numerical model is accurate for the operating conditions commonly encountered at FSAE competitions. It is also concluded that OEM radiators do not provide sufficient cooling for their respective engines when restricted by the rules and regulations of FSAE competitions.

\section{ACKNOWLEDGMENT}

The authors would like to thank the management of PES University for the financial and moral support to carry out this work.

\section{REFERENCES}

[1] Kuntzer, G., Mario, E.S., Martins, Bayer, F.M., Soliman, P.A., Sangaletti, M. (2015). Development of a FSAE racecar cooling system. SAE TECHNICAL PAPER SERIES, No. 2015-36-0409.

[2] Bahuguna, R., Prasad, T., Khanna, R., Kumar, A.B., Gopal, K.N., Srivastava, S., Mishra, A. (2018). Design and development of cooling system for a formula SAE race car. SAE Technical Paper No. 2018-01-0079.

[3] Patel, S., Deshmukh, S.P. (2017). Analytical design and verification of automotive radiator using 1-D simulation. International Journal for Research in Applied Science \& Engineering Technology, 5(XI): 2349-2360. https://doi.org/10.22214/IJRASET.2017.11330

[4] Sathyanarayanan, P.L., Ramprabhu, R. (2005). Study on the effect of different combinations of engine coolant additives on the heat dissipation rate of radiators. Journal of Automobile Engineers, 219(10): 1173-1179. https://doi.org/10.1243/095440705X34838

[5] Elias, M.M., Mahbubul, I.M., Saidur, R., Sohel, M.R., Shahrul, I.M, Khaleduzzaman, S.S., Sadeghipour, S. (2014). Experimental investigation on the thermophysical properties of $\mathrm{Al}_{2} \mathrm{O}_{3}$ nanoparticles suspended in car radiator coolant. International Communication in Heat and Mass Transfer, 54: 48-53. https://doi.org/10.1016/j.icheatmasstransfer.2014.03.00 5

[6] Afrand, M. (2017). Experimental study on thermal conductivity of ethylene glycol containing hybrid nanoadditives and development of a new correlation. Applied
Thermal Engineering, 110: 1111-1119. https://doi.org/10.1016/j.applthermaleng.2016.09.024

[7] Sandhya, D., Chandra Sekhara Reddy, M., Veeredhi, Rao, V. (2016). Improving the cooling performance of automobile radiator with ethylene glycol water based $\mathrm{TiO}_{2}$ nanofluids. International Communications in Heat and Mass Transfer, 78: 121-126. https://doi.org/10.1016/j.icheatmasstransfer.2016.09.00 2

[8] 2020 Formula Bharat Rules Booklet, pages 48 and 49. https://drive.google.com/drive/folders/1WWqsY7mxP M6wrSVKoWkxL3Pav2ewURzm.

[9] Selim, A.B., de Lyra, B. (2016). Cooling package selection through radiator area/material and fan blade angle variation. SAE Technical Paper 2016-36-0370.

[10] Zhang, C., Uddin, M., Robinson, A.C., Foster, L. (2018). Full vehicle CFD investigations on the influence of frontend configuration on radiator performance and cooling drag. Applied Thermal Engineering, 130: 1328-1340. https://doi.org/10.1016/j.applthermaleng.2017.11.086

[11] Ribeiro, E.G., de Andrade Filho, A.P., de Carvalho Meira, J.L. (2007). Electric water pump for engine cooling. SAE Technical Paper 2007-01-2785.

[12] Beard, R.A., Smith, G.J. (1971). A method of calculating the heat dissipation from radiators to cool vehicle engines. SAE Technical Paper 710208.

[13] Navarro, H.A., Cabezas-Gómez, L.C. (2007). Effectiveness-NTU computation with a mathematical model for cross-flow heat exchangers. Brazilian Journal of Chemical Engineering, 24(4): 509-521. https://doi.org/10.1590/S0104-66322007000400005

\section{NOMENCLATURE}

A cross sectional area of the fin, $\mathrm{m}^{2}$

$C \quad$ heat capacity, $\mathrm{J} / \mathrm{s}-\mathrm{K}$

$c_{p} \quad$ specific heat capacity of the coolant water at constant pressure, $\mathrm{J} / \mathrm{kg}-\mathrm{K}$

$h \quad$ convective heat transfer coefficient of the air flowing over the surface of the fins, $\mathrm{W} / \mathrm{m}^{2} \mathrm{~K}$

$k$ thermal conductivity of the fin material, $\mathrm{W} / \mathrm{mK}$

$L \quad$ length of the fin, $m$

$\dot{m}_{w} \quad$ mass flow rate of coolant water through the radiator, $\mathrm{kg} / \mathrm{s}$

NTU Number of Transfer Units

$P \quad$ perimeter of the fin cross section, $m$

$\dot{Q} \quad$ rate of heat transfer, W

$T$ temperature, $\mathrm{K}$

$U$ overall heat transfer coefficient of the radiator, $\mathrm{W} / \mathrm{m}^{2} \mathrm{~K}$

\section{Greek letters}

$\varepsilon \quad$ effectiveness of the radiator

$\eta_{\text {fin }} \quad$ fin efficiency

\section{Subscripts}

c cold fluid

e engine

h hot fluid

min minimum

$\max$ maximum

$\mathrm{r} \quad$ radiator 